\title{
A New Similarity Measure of Picture Fuzzy Sets and Application in the Fault Diagnosis of Steam Turbine
}

\author{
Ngoc Minh Chau \\ Faculty of Information Technology, Vietnam National University of Agriculture, Trau Quy, Gia Lam, Ha Noi, Viet \\ Nam. \\ E-mail:nmchau@vnua.edu.vn

\section{Nguyen Thi Lan, Nguyen Xuan Thao*} \\ Faculty of Information Technology, Vietnam National University of Agriculture, Trau Quy, Gia Lam, Ha Noi, Viet \\ Nam. \\ E-mail: ngtlan@vnua.edu.vn; nxthao@vnua.edu.vn*
}

Received: 08 May 2020; Accepted: 15 July 2020; Published: 08 October 2020

\begin{abstract}
Picture fuzzy set is an extension of fuzzy sets and intuitionistic sets. It is demonstrated have a wide application in the fact and theoretical. In this paper, we propose some novel similarity measures between picture fuzzy sets. The novel similarity measure is constructed by combining negative functions of each degree membership of picture fuzzy set. This similarity is shown that is better other similarity measures of picture fuzzy sets in some cases. Next, we apply them in several pattern recognition problems. Finally, we apply them to find the fault diagnosis of the steam turbine.
\end{abstract}

Index Terms: Picture fuzzy set, similarity measure, fault turbine.

\section{Introduction}

In 2014, Cuong introduced the picture fuzzy set [4]. It is a generalization of Zadeh's fuzzy set [30] and intuitionistic fuzzy set [1, 2, 3]. A picture fuzzy set (PFS) consider three degrees: the positive membership function, the neural membership and negative-membership function. As in a vote, a candidate may receive votes of support, opposition, or abstention (neither support nor opposition). These are respectively the positive membership function, the neural membership and negative-membership function in picture fuzzy set. From its inception to the present day, PFSs have been proven to be a very effective tool for processing uncertainties in real-world problems: the pattern recognition, the decision making...There are the theoretical results bases on picture fuzzy set as: picture fuzzy database was introduced by Dinh et al [5], some aspects of picture fuzzy sets as $(\alpha, \theta, \lambda)$ - cut and the height of a picture fuzzy set was studied by Dutta and Ganju [9], Thao and Dịnh studied rough picture fuzzy set that is combined the picture fuzzy set and the crisp approximations and investigated the picture topologies generated by rough picture fuzzy set [17]. As opposed to fuzzy sets, picture fuzzy set also have broad applications for uncertain data processing such as decision making, economic, medical diagnose, agriculture [6-8, 12, 14-20, 19-20, 22-24, 26]. Along with distance measures [8, 16], correlation measures [14], similar measures [22, 27-29] of picture fuzzy sets are also studied and widely used in many areas and now it is a hot topic. The similarity measure of picture fuzzy sets is useful to handle the problems in many areas: decision making, machine learning, pattern recognition [22, 27- 29]. Wei [28] proposed the similarity measure between picture fuzzy sets based on the cosine functions and applied it in the MCDM. After that, Wei [29] also developed the similarity measure constructed by the distance measure in multiple attribute decision making and recognition problem... The proposed methods constructed by combining negative functions of each degree membership of picture fuzzy set. Some of them have restrictions as non-determined with the picture number $(0,0,0)$. The similarity measure of Wei [28] having $s(\mathrm{~A}, \mathrm{~B})=1 \mathrm{for}$ all picture fuzzy sets $A=k B(k \neq 0)$. This is not good when use it to the application problems.

In this paper, we introduce the new similarity measure of picture fuzzy sets which built by using negative functions for all membership, non-membership and neutral membership functions. These measures are verified to overcome the restriction of some existing other measures. At the same time, we also apply new measures in the problem of pattern recognition and multi-criteria decision-making. The rest of this paper is organized as follows. In Section 2, we recall the 
concept of picture fuzzy set and the similarity measure of them. In this section, we also construct the new similarity measure between the PFSs and give an example demonstrate our measure to recognize the pattern. Finally, we propose a picture fuzzy software quality model in section 4 and give an example to illustrate for the proposed model.

\section{A new similarity measure of the PFSs}

In this section, we introduce the concept of picture fuzzy sets and the similarity measures of them. Next, we proposed the formula to define the new similarity measures of picture fuzzy sets.

Let $X$ be a universal set. We have

Definition 1[4]. A picture fuzzy set on $X$ is a defined by form

$$
A=\left\{\left(x, \mu_{A}(x), \eta_{A}(x), v_{A}(x)\right) \mid x \in X\right\}
$$

in which $\mu_{A}(x) \in[0,1], \eta_{A}(x) \in[0,1]$ and $v_{A}(x) \in[0,1]$ are the membership degree, the neural degree and the nonmembership degree of the element ${ }^{X}$ in $X$ to $A$, respectively, and

$$
\mu_{A}(x)+\eta_{A}(x)+v_{A}(x) \leq 1, \forall x \in X .
$$

We denote $P F S(\mathrm{X})$ is a collection of picture fuzzy set on $X$. In which $X=\{(\mathrm{x}, 1,0,0) \mid \mathrm{x} \in \mathrm{X}\}$ and $\varnothing=\{(\mathrm{x}, 0,0,1) \mid x \in X\}$

For convenience in this paper, we call $P=(a, b, c)$ is a picture fuzzy number if $a, b, c \geq 0$ and $a+b+c \leq 1$.

For two picture fuzzy sets $A, B \in \operatorname{PFS}(X)$ we have:

- $A \subset B$ if only if $\mu_{A}(x)<\mu_{B}(x), \eta_{A}(x) \leq \eta_{B}(x)$ and $v_{A}(x)>v_{B}(x)$ for all $x \in X$.

- $A=B$ if only if $\mu_{A}(x)=\mu_{B}(x), \eta_{A}(x)=\eta_{B}(x)$ and $v_{A}(x)=v_{B}(x)$ for all $x \in X$.

Now, we recall the similarity measure in literal.

Given $X=\left\{x_{1}, x_{2}, \ldots, x_{n}\right\}$ is a universal set. And

$$
\begin{gathered}
A=\left\{\left(x_{i}, \mu_{A}\left(x_{i}\right), \eta_{A}\left(x_{i}\right), v_{A}\left(x_{i}\right)\right) \mid x_{i} \in X\right\}, \\
B=\left\{\left(x_{i}, \mu_{B}\left(x_{i}\right), \eta_{B}\left(x_{i}\right), v_{B}\left(x_{i}\right)\right) \mid x_{i} \in X\right\} \\
\text { are two PFSs on } X .
\end{gathered}
$$

Definition 2: A mapping $\mathrm{S}: \operatorname{PFS}(X) \times \operatorname{PFS}(X) \rightarrow[0,1]$ is a similarity measure of two picture fuzzy sets if it satisfies the following conditions:

(S1) $0 \leq \mathrm{S}(\mathrm{A}, \mathrm{B}) \leq 1, \forall \mathrm{A}, \mathrm{B} \in \operatorname{PFS}(X)$.

(S2) $\mathrm{S}(\mathrm{A}, \mathrm{B})=\mathrm{S}(\mathrm{B}, \mathrm{A}), \forall \mathrm{A}, \mathrm{B} \in \operatorname{PFS}(X)$.

(S3) $\mathrm{S}(\mathrm{A}, \mathrm{A})=1, \forall \mathrm{A} \in \operatorname{PFS}(X)$.

(S4) For all $\mathrm{A}, \mathrm{B}, \mathrm{C} \in \operatorname{PFS}(X)_{\text {such that }} A \subseteq B \subseteq C$ then

$$
S(A, C) \leq \min \{S(A, B), S(B, C)\} .
$$

Now, we proposed the new similarity measures of picture fuzzy sets. After that, we have shown the benefit of new measures by comparing them with other existing similarity measures.

Let $X=\left\{x_{1}, x_{2}, \ldots, x_{n}\right\}$ be a finite set, $A$ and $B$ are two arbitrary PFSs in $X$.We denote

$$
S_{i}^{\mu}(A, B)=1-\left|\mu_{A}\left(x_{i}\right)-\mu_{B}\left(x_{i}\right)\right|, S_{i}^{\eta}(A, B)=1-\left|\eta_{A}\left(x_{i}\right)-\eta_{B}\left(x_{i}\right)\right|, S_{i}^{v}(A, B)=1-\left|v_{A}\left(x_{i}\right)-v_{B}\left(x_{i}\right)\right|
$$

for all $i=1,2, \ldots, n$.

Definition 3. A mapping $\mathrm{S}: \operatorname{PFS}(X) \times \operatorname{PFS}(X) \rightarrow[0,1]$ is defined by

$$
\mathrm{S}_{0}(A, B)=\frac{1}{n} \sum_{i=1}^{n} S_{i}^{0}(A, B)
$$


where $S_{i}^{0}(A, B)=S_{i}^{\mu}(A, B) \times S_{i}^{\eta}(A, B) \times S_{i}^{v}(A, B)$

Theorem 1. Let $A$ and $B$ be two arbitrary PFSs in $X$. The function $\mathrm{S}(A, B)$ in Eq.(1) satisfies the following conditions:

(S1) $0 \leq \mathrm{S}_{0}(A, B) \leq 1, \forall \mathrm{A}, \mathrm{B} \in \operatorname{PFS}(X)$.

(S2) $\mathrm{S}_{0}(A, B)=\mathrm{S}_{0}(A, B), \forall \mathrm{A}, \mathrm{B} \in \operatorname{PFS}(X)$.

(S3) $\mathrm{S}_{0}(\mathrm{~A}, \mathrm{~A})=1, \forall \mathrm{A} \in \operatorname{PFS}(X)$.

(S4) For all $\mathrm{A}, \mathrm{B}, \mathrm{C} \in \mathrm{PFS}(X)$ such that $A \subseteq B \subseteq C$ then

$$
S_{0}(A, C) \leq \min \left\{S_{0}(A, B), S_{0}(B, C)\right\} .
$$

It means that

$$
\mathrm{S}_{0}(A, B)=\frac{1}{n} \sum_{i=1}^{n} S_{i}^{\mu}(A, B) \times S_{i}^{\eta}(A, B) \times S_{i}^{v}(A, B)
$$

is a similarity measure of two picture fuzzy sets.

Proof.

(S1). We have

$0 \leq S_{i}^{\mu}(A, B)=1-\left|\mu_{A}\left(x_{i}\right)-\mu_{B}\left(x_{i}\right)\right| \leq 1,0 \leq S_{i}^{\eta}(A, B)=1-\left|\eta_{A}\left(x_{i}\right)-\eta_{B}\left(x_{i}\right)\right| \leq 1$

and $0 \leq S_{i}^{v}(A, B)=1-\left|v_{A}\left(x_{i}\right)-v_{B}\left(x_{i}\right)\right| \leq 1$ for all $A, B \in P F S(X)$. So that $0 \leq S_{i}^{0}(A, B) \leq 1$.

Hence $0 \leq \mathrm{S}_{0}(A, B)=\frac{1}{n} \sum_{i=1}^{n} S_{i}^{0}(A, B) \leq 1$ for all $A, B \in P F S(X)$.

(S2). It is obvious.

(S3). Considering two picture fuzzy sets $A, B$ on $X$. If $A=B$ then $\mu_{A}\left(x_{i}\right)=\mu_{B}\left(x_{i}\right), \eta_{A}\left(x_{i}\right)=\eta_{B}\left(x_{i}\right)$, $v_{A}\left(X_{i}\right)=v_{B}\left(x_{i}\right)$ according to the Eq.(1) we have

$S_{i}^{\mu}(A, B)=1, S_{i}^{\eta}(A, B)=1$ and $S_{i}^{\nu}(A, B)=1$. So that

$\mathrm{S}_{0}(A, B)=\frac{1}{n} \sum_{i=1}^{n} S_{i}^{\mu}(A, B) \times S_{i}^{\eta}(A, B) \times S_{i}^{v}(A, B)=1$.

(S4). For all $\mathrm{A}, \mathrm{B}, \mathrm{C} \in \mathrm{PFS}(X)$ such that $\mathrm{A} \subseteq \mathrm{B} \subseteq \mathrm{C}$ then $\mu_{A}\left(x_{i}\right) \leq \mu_{B}\left(x_{i}\right) \leq \mu_{C}\left(x_{i}\right)$, $\eta_{A}\left(x_{i}\right) \leq \eta_{B}\left(x_{i}\right) \leq \eta_{C}\left(x_{i}\right)$, and $v_{C}\left(x_{i}\right) \geq v_{B}\left(x_{i}\right) \geq v_{A}\left(x_{i}\right)$. So that

$\max \left\{\left|\mu_{A}\left(x_{i}\right)-\mu_{B}\left(x_{i}\right)\right|,\left|\mu_{B}\left(x_{i}\right)-\mu_{C}\left(x_{i}\right)\right|\right\} \leq\left|\mu_{A}\left(x_{i}\right)-\mu_{C}\left(x_{i}\right)\right|$,

$\max \left\{\left|\eta_{A}\left(x_{i}\right)-\eta_{B}\left(x_{i}\right)\right|,\left|\eta_{B}\left(x_{i}\right)-\eta_{C}\left(x_{i}\right)\right|\right\} \leq\left|\eta_{A}\left(x_{i}\right)-\eta_{C}\left(x_{i}\right)\right|$,

and $\max \left\{\left|v_{A}\left(x_{i}\right)-v_{B}\left(x_{i}\right)\right|,\left|v_{B}\left(x_{i}\right)-v_{C}\left(x_{i}\right)\right|\right\} \leq\left|v_{A}\left(x_{i}\right)-v_{C}\left(x_{i}\right)\right|$.

Then we have

$$
\begin{aligned}
& \min \left\{-\left|\mu_{A}\left(x_{i}\right)-\mu_{B}\left(x_{i}\right)\right|,-\left|\mu_{B}\left(x_{i}\right)-\mu_{C}\left(x_{i}\right)\right|\right\} \geq-\left|\mu_{A}\left(x_{i}\right)-\mu_{C}\left(x_{i}\right)\right|, \\
& \min \left\{-\left|\eta_{A}\left(x_{i}\right)-\eta_{B}\left(x_{i}\right)\right|,-\left|\eta_{B}\left(x_{i}\right)-\eta_{C}\left(x_{i}\right)\right|\right\} \geq-\left|\eta_{A}\left(x_{i}\right)-\eta_{C}\left(x_{i}\right)\right|,
\end{aligned}
$$


and

$$
\min \left\{-\left|v_{A}\left(x_{i}\right)-v_{B}\left(x_{i}\right)\right|,-\left|v_{B}\left(x_{i}\right)-v_{C}\left(x_{i}\right)\right|\right\} \geq-\left|v_{A}\left(x_{i}\right)-v_{C}\left(x_{i}\right)\right| .
$$

Since, we obtain

$S_{i}^{\mu}(A, C) \leq \min \left\{S_{i}^{\mu}(A, B), S_{i}^{\mu}(B, C)\right\}, S_{i}^{\eta}(A, C) \leq \min \left\{S_{i}^{\eta}(A, B), S_{i}^{\eta}(B, C)\right\}$

and

$S_{i}^{v}(A, C) \leq \min \left\{S_{i}^{v}(A, B), S_{i}^{v}(B, C)\right\}$.

Hence, we have

$S_{i}^{0}(A, C) \leq \min \left\{S_{i}^{0}(A, B), S_{i}^{0}(B, C)\right\}$.

So that

$S_{0}(A, C) \leq \min \left\{S_{0}(A, B), S_{0}(B, C)\right\}$

Now, we can define the similarity measure of the picture fuzzy sets that assigned with the weight of each element in the universal set.

We assume that each element $x_{i}$ in the universal $X=\left\{x_{1}, x_{2}, \ldots, x_{n}\right\}$ which assigned with a weight $\omega_{i} \in[0,1]$ for $i=1,2, \ldots, n$ such that $\sum_{i=1}^{n} \omega_{i}=1$.

Definition 4. A mapping $S: \operatorname{IFS}(X) \times \operatorname{IFS}(X) \rightarrow[0,1]$ is defined by $S_{0}^{\omega}(A, B)=\sum_{i=1}^{n} \omega_{i} S_{i}^{0}(A, B)$

Theorem 2. Let $A$ and $B$ be two arbitrary PFSs in $X$. The function $S_{0}^{\omega}(A, B)$ in Eq.(2) satisfies the following conditions:

(S1) $0 \leq \mathrm{S}_{0}^{\omega}(\mathrm{A}, \mathrm{B}) \leq 1, \forall \mathrm{A}, \mathrm{B} \in \operatorname{PFS}(X)$.

(S2) $\mathrm{S}_{0}^{\omega}(\mathrm{A}, \mathrm{B})=\mathrm{S}_{0}^{\omega}(\mathrm{B}, \mathrm{A}), \forall \mathrm{A}, \mathrm{B} \in \operatorname{PFS}(X)$.

(S3) $\mathrm{S}_{0}^{\omega}(\mathrm{A}, \mathrm{A})=1, \forall \mathrm{A} \in \operatorname{PFS}(X)$.

(S4) For all A,B, $C \in \operatorname{PFS}(X)$ such that $A \subseteq B \subseteq C$ then $\mathrm{S}_{0}^{\omega}(A, C) \leq \min \left\{\mathrm{S}_{0}^{\omega}(A, B), \mathrm{S}_{0}^{\omega}(B, C)\right\}$.

It means that

$$
\mathrm{S}_{0}^{\omega}(A, B)=\sum_{i=1}^{n} \omega_{i} S_{i}^{0}(A, B)
$$

is a similarity measure of two picture fuzzy sets.

\section{Proof.}

(S1) Because

$0 \leq S_{i}^{\mu}(A, B), S_{i}^{\eta}(A, B), S_{i}^{v}(A, B) \leq 1$.

We have $0 \leq \mathrm{S}_{0}^{\omega}(A, B)=\sum_{i=1}^{n} \omega_{i} S_{i}^{0}(A, B) \leq \frac{1}{n} \sum_{i=1}^{n} \omega_{i}=1$.

(S2). It is obviously.

(S3). If $\mathrm{A}=\mathrm{B}$ then $\mu_{A}\left(x_{i}\right)=\mu_{B}\left(x_{i}\right), \eta_{A}\left(x_{i}\right)=\eta_{B}\left(x_{i}\right), v_{A}\left(x_{i}\right)=v_{B}\left(x_{i}\right)$ according to the Eq.(2) we have $S_{i}^{\mu}(A, B)=1, S_{i}^{\eta}(A, B)=1, S_{i}^{v}(A, B)=1$. So that 
$\mathrm{S}_{0}^{\omega}(A, B)=\sum_{i=1}^{n} \omega_{i} S_{i}^{0}(A, B)=\frac{1}{n} \sum_{i=1}^{n} \omega_{i}=1$

(S4). For all $A, B, C \in \mathrm{PFS}(X)$ such that $\mathrm{A} \subseteq \mathrm{B} \subseteq \mathrm{C}$ then

$S_{i}^{\mu}(A, C) \leq \min \left\{S_{i}^{\mu}(A, B), S_{i}^{\mu}(B, C)\right\}, S_{i}^{\eta}(A, C) \leq \min \left\{S_{i}^{\eta}(A, B), S_{i}^{\eta}(B, C)\right\}$

and

$$
S_{i}^{v}(A, C) \leq \min \left\{S_{i}^{v}(A, B), S_{i}^{v}(B, C)\right\}
$$

Hence

$$
S_{i}^{0}(A, C) \leq \min \left\{S_{i}^{0}(A, B), S_{i}^{0}(B, C)\right\}
$$

So that

$\mathrm{S}_{0}^{\omega}(A, C)=\sum_{i=1}^{n} \omega_{i} S_{i}^{0}(A, C) \leq \frac{1}{n} \sum_{i=1}^{n} \omega_{i} \min \left\{S_{i}^{0}(A, B), S_{i}^{0}(B, C)\right\}=\min \left\{\mathrm{S}_{0}^{\omega}(\mathrm{A}, \mathrm{B}), \mathrm{S}_{0}^{\omega}(\mathrm{B}, \mathrm{C})\right\}$.

\section{Compare with some other similarity measures:}

Now, we consider an example to compare our proposed similarity measures and some other similarity measures on picture fuzzy sets which introduced by Wei in [28, 29].

+Cosine similarity measure

$$
\mathrm{S}_{C}(A, B)=\frac{1}{n} \sum_{i=1}^{n} \frac{\mu_{A}\left(x_{i}\right) \mu_{B}\left(x_{i}\right)+\eta_{A}\left(x_{i}\right) \eta_{B}\left(x_{i}\right)+v_{A}\left(x_{i}\right) v_{B}\left(x_{i}\right)}{\sqrt{\mu_{A}\left(x_{i}\right)^{2}+\eta_{A}\left(x_{i}\right)^{2}+v_{A}\left(x_{i}\right)^{2}} \sqrt{\mu_{B}\left(x_{i}\right)^{2}+\eta_{B}\left(x_{i}\right)^{2}+v_{B}\left(x_{i}\right)^{2}}}
$$

+ Dice similarity measure

$$
\begin{aligned}
& \mathrm{S}_{C 1}(A, B)=\frac{1}{n} \sum_{i=1}^{n} \frac{\mu_{A}\left(x_{i}\right) \mu_{B}\left(x_{i}\right)+\eta_{A}\left(x_{i}\right) \eta_{B}\left(x_{i}\right)+v_{A}\left(x_{i}\right) v_{B}\left(x_{i}\right)}{\max \left(\mu_{A}\left(x_{i}\right)^{2}+\eta_{A}\left(x_{i}\right)^{2}+v_{A}\left(x_{i}\right)^{2}, \mu_{B}\left(x_{i}\right)^{2}+\eta_{B}\left(x_{i}\right)^{2}+v_{B}\left(x_{i}\right)^{2}\right)} \\
& \text { + Grey similarity measure } \\
& \mathrm{S}_{G}(A, B)=\frac{1}{3 n} \sum_{i=1}^{n}\left(\frac{\Delta \mu_{\min }+\Delta \mu_{\max }}{\Delta \mu+\Delta \mu_{\max }}+\frac{\Delta \eta_{\min }+\Delta \eta_{\max }}{\Delta \eta+\Delta \eta_{\max }}+\frac{\Delta v_{\text {min }}+\Delta v_{\max }}{\Delta v+\Delta v_{\max }}\right)
\end{aligned}
$$

where $\Delta \mu_{i}=\left|\mu_{A}\left(x_{i}\right)-\mu_{B}\left(x_{i}\right)\right|, \Delta \mu_{\text {min }}=\min \left\{\Delta \mu_{i}\right\}, \Delta \mu_{\text {max }}=\max \left\{\Delta \mu_{i}\right\}, \Delta \eta_{i}=\left|\eta_{A}\left(x_{i}\right)-\eta_{B}\left(x_{i}\right)\right|, \Delta \eta_{\text {min }}=\min \left\{\Delta \eta_{i}\right\}$, $\Delta \eta_{\max }=\max \left\{\Delta \eta_{i}\right\}, \Delta v_{i}=\left|v_{A}\left(x_{i}\right)-v_{B}\left(x_{i}\right)\right|, \Delta v_{\min }=\min \left\{\Delta v_{i}\right\}$.

+ The similarity measures based on cosine function

$$
\mathrm{S}_{C O S 1}(A, B)=\frac{1}{n} \sum_{i=1}^{n} \operatorname{COS}\left(\frac{\pi}{2} \max \left\{\begin{array}{l}
\left|\mu_{A}\left(x_{i}\right)-\mu_{A}\left(x_{i}\right)\right|, \\
\left|\eta_{A}\left(x_{i}\right)-\eta_{A}\left(x_{i}\right)\right|, \\
\left|\nu_{A}\left(x_{i}\right)-v_{A}\left(x_{i}\right)\right|
\end{array}\right\}\right)
$$

and

$$
\mathrm{S}_{\operatorname{COS2}}(A, B)=\frac{1}{n} \sum_{i=1}^{n} \operatorname{COS}\left(\frac{\pi}{4}\left\{\begin{array}{l}
\left|\mu_{A}\left(x_{i}\right)-\mu_{A}\left(x_{i}\right)\right|+ \\
\left|\eta_{A}\left(x_{i}\right)-\eta_{A}\left(x_{i}\right)\right|+ \\
\left|v_{A}\left(x_{i}\right)-v_{A}\left(x_{i}\right)\right|
\end{array}\right\}\right)
$$

Example 1. Suppose that $A$ and $B$ are two PFSs in 
$X=\{x\}$ where $A=\{(x, 0,0,0)\}$ and $B=\{(x, 0,0,0)\}$. We easy see that $S_{C}(A, B)=$ Null , $S_{C 1}(A, B)=$ Null,$S_{G}(A, B)=$ Null . This result is not suitable to the condition (S3) in the definition 3. Our similarity measure satisfies this condition $S_{0}(A, B)=1$.

Example 2. Suppose that $A$ and $B$ are two pattern PFSs in $X=\left\{x_{1}, x_{2}\right\}$ where

$$
A=\left\{\left(x_{1}, 0.1,0,0.1\right),\left(x_{2}, 0,0.4,0.4\right)\right\}, B=\left\{\left(x_{1}, 0.1,0.1,0\right),\left(x_{2}, 0.1,0,0.1\right)\right\}
$$

and if we have sample PFSs in $X=\left\{x_{1}, x_{2}\right\}$

$$
C=\left\{\left(x_{1}, 0,0.1,0.1\right),\left(x_{2}, 0,0.2,0.2\right)\right\} .
$$

Question: Which pattern does $C$ belong to?

Using the above similarity measures, we obtain $\mathrm{S}_{0}(A, C)=0.725, \mathrm{~S}_{0}(B, C)=0.729$ so that $C$ belong to the class of pattern $B$.

This result is coincide with the result using the similarity $\mathrm{S}_{G}$, specifically $\mathrm{S}_{G}(A, C)=0.77, \mathrm{~S}_{G}(B, C)=0.86$. If using the similarity measure $\mathrm{S}_{\operatorname{COS} 1}$ and $\mathrm{S}_{\operatorname{COS} 2}$ we cannot put $C$ belong to the class of $A$ or $B$ because $\mathrm{S}_{C O S 1}(A, C)=\mathrm{S}_{C O S 1}(B, C)=0.97$ and $\mathrm{S}_{C O S 1}(A, C)=\mathrm{S}_{C O S 1}(B, C)=0.97$. These examples are showed the meaningful of new similarity measures.

\section{Application the picture similarity measure in the fault diagnosis of steam turbine}

In this section, we apply our proposed similarity measure to predict the fault diagnosis of steam turbine. Data is cited in [25] (see Table 1). In this data, we see that each error pattern has the form of a picture fuzzy set on the set of attributes. Moreover, a picture fuzzy set is also called a standard neutrosophic set $[17,18]$. So that it is motivation for us to apply our proposed similarity measure on the picture fuzzy set to diagnose errors for steam turbines.

There are a set of ten fault patterns $A=\left\{A_{1}, A_{2}, A_{3}, A_{4}, A_{5}, A_{6}, A_{7}, A_{8}, A_{9}, A_{10}\right\}$ in which $A_{1}$ : Unbalance; ${ }_{2}$ : Pneumatic force couple; ${ }^{A_{3}}$ : Offset center; ${ }^{A_{4}}$ : Oil-membrane oscillation; $A_{5}$ : Radial impact friction of rotor; $A_{6}$ : Symbiosis looseness; ${ }^{A_{7}}$ : Damage of antithrust bearing; ${ }^{A_{8}}$ : Surge; ${ }^{A_{9}}$ : Looseness of bearing block; ${ }^{A_{10}}$ : Non-uniform bearing stiffness.

Each fault pattern is a picture fuzzy set on a set of nine frequency ranges for different frequency spectrum

$$
C=\left\{\begin{array}{l}
C_{1}(0.01 ? .39 f), C_{2}(0.4 ? .49 f), C_{3}(0.5 f), \\
C_{4}(0.51 ? .99 f), C_{5}(f), C_{6}(2 f), C_{7}(3-5 f), \\
C_{8}(\text { Odd times of } f), C_{9}(\text { High frequency }>5 f)
\end{array}\right\}
$$

There are two fault sample are picture fuzzy sets $B_{1}$ and $B_{2}$ on the set of attributes $C$ as in Table 2 .

Question: Which fault pattern do $B_{1}$ and $B_{2}$ belong to?

To solve this problem, we do it in two steps

Step 1.Determine the weight of each attribute, we assume that the weight of each attribute $C_{j}$ is $\omega_{j}=\frac{1}{9}$ for all $j=1,2, \ldots, 9$.

Step 2. Compute the similarity measure $s\left(B_{i}, A_{j}\right)$ between $B_{i}(i$ 구 , 2$)$ and $A_{j}(j=1,2, \ldots, 10)$ by using eq.(1) to rank order of all faults. For the sample $B_{i}$ we have $A_{j} \succ A_{k}$ if $s\left(B_{i}, A_{j}\right)>s\left(B_{i}, A_{k}\right)$ where $A_{j} \succ A_{k}$ means that $A_{j}$ having the higher order than $A_{k}$. The computing results is shown in Table 3. 
Step 3. Chose the fault having the highest rank. For the sample $B_{1}$ we put it belong to the fault pattern $A_{7}$. For the sample $B_{2}$ we put it belong to the fault pattern $A_{9}$ (See Table 3).

These results are consistent with the results by using similarity measures based on cotangent function of the neutrosophic set and experience in [25].

Table 1. The fault patterns with picture fuzzy number values

\begin{tabular}{|c|c|c|c|c|c|}
\hline & $A_{1}$ & $A_{2}$ & $A_{3}$ & $A_{4}$ & $A_{5}$ \\
\hline$C_{1}$ & $<0,0,1>$ & $<0,0,1>$ & $<0,0,1>$ & $<0.09,0.02,0.89>$ & $<0.09,0.03,0.88>$ \\
\hline$C_{2}$ & $<0,0,1>$ & $<0.28,0.03,0.69>$ & $<0,0,1>$ & $<0.78,0.04,0.18>$ & $<0.09,0.02,0.89>$ \\
\hline$C_{3}$ & $<0,0,1>$ & $<0.09,0.03,0.88>$ & $<0,0,1>$ & $<0,0,1>$ & $<0.08,0.04,0.88>$ \\
\hline$C_{4}$ & $<0,0,1>$ & $<0.55,0.15,0.3>$ & $<0,0,1>$ & $<0.08,0.03,0.89>$ & $<0.09,0.03,0.88>$ \\
\hline$C_{5}$ & $<0.85,0.15,0>$ & $<0,0,1>$ & $<0.03,0.28,0.42>$ & $<0,0,1>$ & $<0.18,0.03,0.79>$ \\
\hline$C_{6}$ & $<0.04,0.02,0.94>$ & $<0,0,1>$ & $<0.04,0.22,0.38>$ & $<0,0,1>$ & $<0.08,0.05,0.87>$ \\
\hline$C_{7}$ & $<0.04,0.03,0.93>$ & $<0,0,1>$ & $<0.08,0.05,0.87>$ & $<0,0,1>$ & $<0.08,0.05,0.87>$ \\
\hline$C_{8}$ & $<0,0,1>$ & $<0,0,1>$ & $<0,0,1>$ & $<0,0,1>$ & $<0.08,0.04,0.88>$ \\
\hline$C_{9}$ & $<0,0,1>$ & $<0.08,0.05,0.87>$ & $<0,0,1>$ & $<0,0,1>$ & $<0.08,0.04,0.88>$ \\
\hline
\end{tabular}

Table 2. The fault patterns with picture fuzzy number values (cont.)

\begin{tabular}{|c|c|c|c|c|c|}
\hline & $A_{6}$ & $A_{7}$ & $A_{8}$ & $A_{9}$ & $A_{10}$ \\
\hline$C_{1}$ & $<0,0,1>$ & $<0,0,1>$ & $<0,0,1>$ & $<0.85,0.08,0.07>$ & $<0,0,1>$ \\
\hline$C_{2}$ & $<0,0,1>$ & $<0,0,1>$ & $<0.27,0.05,0.68>$ & $<0,0,1>$ & $<0,0,1>$ \\
\hline$C_{3}$ & $<0,0,1>$ & $<0.08,0.04,0.88>$ & $<0.08,0.04,0.88>$ & $<0,0,1>$ & $<0,0,1>$ \\
\hline$C_{4}$ & $<0,0,1>$ & $<0.86,0.07,0.07>$ & $<0.54,0.08,0.38>$ & $<0,0,1>$ & $<0,0,1>$ \\
\hline$C_{5}$ & $<0.18,0.04,0.78>$ & $<0,0,1>$ & $<0,0,1>$ & $<0,0,1>$ & $<0,0,1>$ \\
\hline$C_{6}$ & $<0.12,0.05,0.83>$ & $<0,0,1>$ & $<0,0,1>$ & $<0,0,1>$ & $<0.77,0.06,0.17>$ \\
\hline$C_{7}$ & $<0.37,0.08,0.55>$ & $<0,0,1>$ & $<0,0,1>$ & $<0,0,1>$ & $<0.19,0.04,0.77>$ \\
\hline$C_{8}$ & $<0,0,1>$ & $<0,0,1>$ & $<0,0,1>$ & $<0.08,0.04,0.88>$ & $<0,0,1>$ \\
\hline$C_{9}$ & $<0.22,0.06,0.72>$ & $<0,0,1>$ & $<0,0,1>$ & $<0,0,1>$ & $<0,0,1>$ \\
\hline
\end{tabular}

Table 3. two fault sample with picture fuzzy number values

\begin{tabular}{|c|c|c|}
\hline & $B_{1}$ & $B_{2}$ \\
\hline$C_{1}$ & $(0,0,1)$ & $(0.39,0,0.61)$ \\
\hline$C_{2}$ & $(0,0,1)$ & $(0.07,0,0.93)$ \\
\hline$C_{3}$ & $(0.1,0,0.9)$ & $(0,0,1)$ \\
\hline$C_{4}$ & $(0.9,0,0.1)$ & $(0.06,0,0.94)$ \\
\hline$C_{5}$ & $(0,0,1)$ & $(0,0,1)$ \\
\hline$C_{6}$ & $(0,0,1)$ & $(0.13,0,0.87)$ \\
\hline$C_{7}$ & $(0,0,1)$ & $(0,0,1)$ \\
\hline$C_{8}$ & $(0,0,1)$ & $(0,0,1)$ \\
\hline$C_{9}$ & $(0,0,1)$ & $(0.35,0,0.65)$ \\
\hline
\end{tabular}


Table 4. The similarity measures of $B_{i}(i=1,2)$ and $A_{j}(j=1,2, \ldots, 10)$

\begin{tabular}{|c|c|c|c|c|c|c|c|c|c|c|}
\hline$s_{0}\left(B_{i}, A_{j}\right)$ & $A_{1}$ & $A_{2}$ & $A_{3}$ & $A_{4}$ & $A_{5}$ & $A_{6}$ & $A_{7}$ & $A_{8}$ & $A_{9}$ & $A_{10}$ \\
\hline$B_{1}$ & 0.6334 & 0.7506 & 0.5667 & 0.6454 & 0.6178 & 0.5672 & $\mathbf{0 . 8 7 9 8}$ & 0.772 & 0.659 & 0.621 \\
\hline$B_{2}$ & 0.5965 & 0.5906 & 0.5484 & 0.6442 & 0.6679 & 0.6497 & 0.5942 & 0.5827 & $\mathbf{0 . 6 9 5}$ & 0.5971 \\
\hline
\end{tabular}

\section{Conclusion}

In this article we have provided the new similarity measures between picture fuzzy sets. Next, we compare our proposed measure with some existing similarity measures. Finally, we apply them in the pattern recognition problem to find fault turbine. These results are consistent with the results by using similarity measures based on cotangent function of the neutrosophic set and experience in [25]. In future, we will find the new measures for picture fuzzy sets and apply it to the real problems, as same as study this approach in other theories as in [3, 13, 21].

\section{References}

[1] K. T. Atanassov, Intuitionistic fuzzy sets, Fuzzy sets and Systems, 20(1) (1986), 87-96.

[2] K. Atanassov, On Intuitionistic Fuzzy Sets Theory, Springer, Berlin, 2012.

[3] K. Atanassov, and G. Gargov, Interval valued intuitionistic fuzzy sets, Fuzzy sets and systems, 31(3) (1989), 343-349.

[4] B.C. Cường, Picture fuzzy sets, Journal of Computer Science and Cybernetics 30.4 (2014): 409-420.

[5] Dinh NV, NX Thao, NM Chau, On the picture fuzzy database: theories and application, Journal of Scientist and Development (2015), 13(6), 1028-1035.

[6] Dinh, N. V., Thao, N. X., \& Chau, N. M. (2017). Some dissimilarity measures of picture fuzzy set. the 10th Fundamental and Applied IT Research (FAIR'2017), 104-109.

[7] Dinh, NV, \& Thao, N. X. (2018). Some measures of picture fuzzy sets and their application in multi-attribute decision making. Int. J. Math. Sci. Comput.(IJMSC), 4(3), 23-41.

[8] Dinh, NV, Thao, N. X., \& Chau, N. M. (2019). Distance and dissimilarity measure of picture fuzzy sets. Proceeding of Publishing House for Science and Technology.

[9] Dutta, P., \& Ganju, S. (2017). Some aspects of picture fuzzy set. Transactions of A. Razmadze Mathematical Institute 172(2), 164-175.

[10] Hoa, N. D., \& Thong, P. H. (2017). Some Improvements of Fuzzy Clustering Algorithms Using Picture Fuzzy Sets and Applications for Geographic Data Clustering. VNU Journal of Science: Computer Science and Communication Engineering, 32(3).

[11] Le, N. T., Van Nguyen, D., Ngoc, C. M., \& Nguyen, T. X. (2018). NEW DISSIMILARITY MEASURES ON PICTURE FUZZY SETS AND APPLICATIONS. Journal of Computer Science and Cybernetics, 34(3), 219-231.

[12] Nguyen, X. T. (2018). Evaluating Water Reuse Applications under Uncertainty: A Novel Picture Fuzzy Multi Criteria Decision Making Medthod. International Journal of Information Engineering and Electronic Business, 10(6), 32-39.

[13] Nhung, L.T., \& Nguyen, X. T. (2018). A novel multi-criteria decision making method for evaluating water reuse applications under uncertainty. Vietnam Journal of Agricultural Sciences, 1(3), 230-239.

[14] Singh, P. (2015). Correlation coefficients for picture fuzzy sets. Journal of Intelligent \& Fuzzy Systems, 28(2), 591-604.

[15] Son LH. (2015). DPFCM: A novel distributed picture fuzzy clustering method on picture fuzzy sets 42(1), 51-66.

[16] Son, L. H. (2016). Generalized picture distance measure and applications to picture fuzzy clustering. Applied Soft Computing, 46(C), 284-295.

[17] Thao, N.X., \& Dinh, N. V. (2015). Rough picture fuzzy set and picture fuzzy topologies. Journal of Computer Science and Cybernetics, 31(3), 245.

[18] Thao, N. X., \& Smarandache, F. (2016). (I, T)-Standard neutrosophic rough set and its topologies properties. V14, pp 65-70.

[19] Thao, N. X., Cuong, B. C., \& Smarandache, F. (2016). Rough standard neutrosophic sets: an application on standard neutrosophic information systems. Infinite Study.

[20] Thao, N. X., Cuong, B. C., Ali, M., \& Lan, L. H. (2018). Fuzzy equivalence on standard and rough neutrosophic sets and applications to clustering analysis. In Information Systems Design and Intelligent Applications (pp. 834-842). Springer, Singapore.

[21] Thao, N.X (2020a). A new correlation coefficient of the Pythagorean fuzzy sets and its applications. Soft Computing 24, 94679478. https://doi.org/10.1007/s00500-019-04457-7.

[22] Thao, N.X (2020b). Similarity measures of picture fuzzy sets based on entropy and their application in MCDM. Pattern Anal Applic 23, 1203-1213 (2020). https://doi.org/10.1007/s10044-019-00861-9

[23] Thong, N. T. (2015). HIFCF: An effective hybrid model between picture fuzzy clustering and intuitionistic fuzzy recommender systems for medical diagnosis. Expert Systems with Applications, 42(7), 3682-3701.

[24] Thong, P. H. (2016). Picture fuzzy clustering: a new computational intelligence method. Soft computing, 20(9), 3549-3562.

[25] Ye, J. (2017). Single-valued neutrosophic similarity measures based on cotangent function and their application in the fault diagnosis of steam turbine. Soft Computing, 21(3), 817-825. 
[26] Wang, C., Zhou, X., Tu, H., \& Tao, S. (2017). Some geometric aggregation operators based on picture fuzzy sets and their application in multiple attribute decision making. Italian Journal of Pure and Applied Mathematics, 37, 477-492.

[27] Wei, G. (2016). Picture fuzzy cross-entropy for multiple attribute decision making problems. Journal of Business Economics and Management, 17(4), 491-502.

[28] Wei, G. (2017). Some cosine similarity measures for picture fuzzy sets and their applications to strategic decision making. Informatica, 28(3), 547-564.

[29] Wei, G. (2018). Some similarity measures for picture fuzzy sets and their applications. Iranian Journal of Fuzzy Systems, 15(1), 77-89.

[30] L. A. Zadeh, Fuzzy sets, Information and control 8(3) (1965), 338-353.

\section{Authors' Profiles}

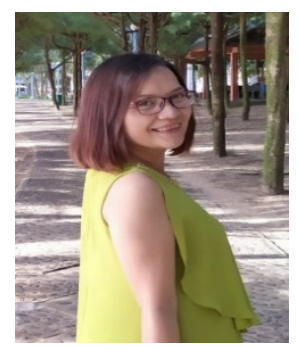

Ngoc Minh Chau received M.S Degrees in Mathematics from The Hanoi National University of Education (HNUE), Hanoi, in 2005. Now, she is a lecturer in Faculty of Mathematics, Vietnam National University of Agriculture (VNUA), Viet Nam. She is teaching Calculus, Optimization, Fuzzy logic and its application. Her research-interests are Spectral theory of operator, Fuzzy set theory, Rough set theory and application in data mining.

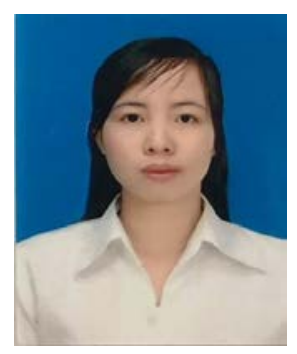

Nguyen Thi Lan received M.S Degrees in Statistics Mathematic from Ha Noi University of Education (VNUE), Hanoi, in 2012. Now, she is a lecturer in Faculty of Information Technology, Vietnam National University of Agriculture (VNUA), Viet Nam. She is teaching basic Math as analysis, probability statistics and linear algebra and specialized subjects as discrete math, information security, ... She researched: "Application of some methods for building classification functions in warning of default risk for Vietnam stock commercial banks”.

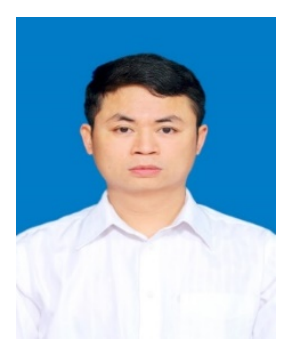

Nguyen Xuan Thao received M.S Degrees in Mathematic from The College of Science Vietnamese National University (VNU), Hanoi, in 2009. Now, he is a lecturer in Faculty of Information Technology, Vietnam National University of Agriculture (VNUA), Viet Nam. He is teaching Calculus, Optimization, Fuzzy logic and its application. His research interests are Spectral theory of operator, Fuzzy set theory, Rough set theory and application in data mining.

How to cite this paper: Ngoc Minh Chau, Nguyen Thi Lan, Nguyen Xuan Thao. " A New Similarity Measure of Picture Fuzzy Sets and Application in the Fault Diagnosis of Steam Turbine ", International Journal of Mathematical Sciences and Computing (IJMSC), Vol.6, No.5, pp.47-55, 2020. DOI: 10.5815/IJMSC.2020.05.05 